\title{
Intervenciones para la disminución de la transmisión de los virus respiratorios
}

\author{
Interventions for reducing respiratory virus transmission
}

\section{Objetivo}

Revisar la evidencia sobre la efectividad de intervenciones físicas para reducir la diseminación de virus respiratorios.

\section{Fuentes de datos}

Se buscaron en Cochrane Library, Medline, OldMedline, Embase y CINAHL, sin restricción de idioma, estudios aleatorizados, cohortes, de casos y controles y estudios controlados antes y después sobre intervenciones para prevenir la transmisión de virus respiratorios (aislamiento, cuarentena, distancia social, barreras, protección personal e higiene).

\section{Selección de estudios}

Sobre 2300 títulos potencialmente relevantes se seleccionaron inicialmente 138. Dos autores en forma independiente aplicaron los criterios de inclusión, y cuatro autores extrajeron los datos y verificaron su precisión.

\section{Extracción de datos}

La calidad de los estudios incluidos fue irregular. Hubo pérdida de información sobre el grado de la aleatorización, la ceguera, las intervenciones, los resultados, el diseño de los estudios y la presencia de confundidores. El acatamiento a las intervenciones, especialmente a los programas educacionales, fue dificultoso en varios estudios, a pesar de la importancia de las intervenciones de bajo costo. Seis estudios de casos y controles evaluaron el impacto de distintas medidas: lavado frecuente de manos, máscaras quirúrgicas comunes y con un 95\% de capacidad de filtración de partículas de aerosol (N95) guantes, y la combinación de todas durante la epidemia de síndrome agudo respiratorio severo (SARS) en China, Singapur y Vietnam durante 2003, siendo éstos últimos estudios los que aportaron mayor consistencia en sus resultados.

\section{Resultados principales}

La implementación de barreras a la transmisión, aislamiento y medidas higiénicas son intervenciones efectivas y de bajo costo para contener epidemias de virus respiratorios como el SARS, con efectos estimados entre 55 y $90 \%$. El efecto incre- mental de la adición de virucidas o antisépticos al lavado de manos permanece incierto. Ver tabla 1.

Tabla 1: resumen de las intervenciones físicas que mostraron efectividad para prevenir la transmisión de virus respiratorios. Los odds ratio representan la asociación estadística (en este caso inversa) documentada entre "haber implementado" la medida de barrera en cuestión y "haberse contagiado".

\begin{tabular}{|c|c|c|c|c|c|c|}
\hline $\begin{array}{l}\text { Procedimiento } \\
\text { y número de } \\
\text { estudios que } \\
\text { lo evaluaron }\end{array}$ & $\begin{array}{c}\text { Lavado } \\
\text { manos más } \\
\text { de diez } \\
\text { veces por } \\
\text { día (6) }\end{array}$ & $\begin{array}{l}\text { Uso de } \\
\text { máscaras } \\
\text { quirúrgicas } \\
\text { simples (5) }\end{array}$ & $\begin{array}{l}\text { Uso de } \\
\text { máscaras } \\
\text { N95 (2) }\end{array}$ & $\begin{array}{l}\text { Uso de } \\
\text { guantes } \\
\text { (4) }\end{array}$ & $\begin{array}{l}\text { Uso de } \\
\text { bata } \\
\text { (4) }\end{array}$ & $\begin{array}{l}\text { Combinación } \\
\text { de las } \\
\text { anteriores } \\
\text { (2) }\end{array}$ \\
\hline $\begin{array}{l}\text { Odds ratio } \\
\text { (IC95\%) }\end{array}$ & $\begin{array}{c}0,45 \\
(0,36 \mathrm{a} \\
0,57)\end{array}$ & $\begin{array}{c}0,32 \\
(0,25 \mathrm{a} \\
0,40)\end{array}$ & $\begin{array}{c}0,09 \\
(0,03 \mathrm{a} \\
0,30)\end{array}$ & $\begin{array}{c}0,43 \\
(0,29 \text { a } \\
0,65)\end{array}$ & $\begin{array}{c}0,23 \\
(0,14 \mathrm{a} \\
0,37)\end{array}$ & $\begin{array}{c}0,09 \\
(0,02 \text { a } \\
0,35)\end{array}$ \\
\hline $\begin{array}{l}\text { NNP } \\
\text { (IC95\%) }\end{array}$ & $\begin{array}{c}4 \\
(3,65 \mathrm{a} \\
5,52)\end{array}$ & $\begin{array}{c}6 \\
(4,54 \mathrm{a} \\
8,03)\end{array}$ & $\begin{array}{c}3 \\
(2,34 \mathrm{a} \\
4,06)\end{array}$ & $\begin{array}{c}7 \\
(4,15 \mathrm{a} \\
5,41)\end{array}$ & $\begin{array}{c}5 \\
(3,37 \mathrm{a} \\
7,12)\end{array}$ & $\begin{array}{c}3 \\
(2,66 \mathrm{a} \\
4,97)\end{array}$ \\
\hline
\end{tabular}

N95: máscaras que filtran el 95\% de las partículas de aerosol. NNP: número necesario de veces que es necesario implementar una medida para prevenir un contagio adicional.

\section{Conclusiones}

Más allá de las dificultades metodológicas, algunas de ellas derivadas de la realización de estudios durante epidemias en situaciones de emergencia y con financiación más reducida que las de los ensayos clínicos con potenciales beneficios económicos, en esta revisión sistemática se encontró que el lavado de manos, el uso de máscaras y el aislamiento de los pacientes infectados son medidas potencialmente eficaces en la prevención de la propagación de las infecciones por virus respiratorios.

Palabras clave:linfecciones respiratorias, propagación, barreras, aislamiento, medidas físicas.

Key words: respiratory infections, transmission, barriers, isolation, physical interventions. Key words: respiratory infections, transm
Conflictos de interés: no declarado.

Conflictos de interés: no declarado. tuciones de cada autor.

\section{Comentario}

La importancia de la higiene para contener epidemias respiratorias se puso de manifiesto con la crisis sanitaria desatada en Asia por el síndrome respiratorio agudo severo (SRAS) cuyo principal reporte de casos hemos resumido y comentado en EVIDENCIA .

Estamos generalmente más predispuestos a someternos a procedimientos complejos que a medidas simples que impliquen cambios de conducta. El lavado de manos es la primera medida que inculcan las autoridades sanitarias cuando existe un brote infeccioso ${ }^{1}$, siendo la principal acción para reducir la transmisión de microorganismos resistentes a los agentes antimicrobianos ${ }^{2}$.

El principal problema no es la dificultad de su práctica, sencilla por cierto, sino la laxitud de su cumplimiento. En este sentido, vale aclarar que el Centro para la Prevención y Control de Enfermedades (CDC) de EEUU realiza campañas nacionales de promoción de un lavado de manos correcto en el ámbito doméstico.

\section{Conclusiones del comentador}

Si bien se requieren trabajos de mayor envergadura y mejor diseño para evaluar las mejores combinaciones de prácticas; mientras tanto, el lavado de manos frecuente (con o sin antisépticos) las medidas de barrera (guantes, batas y máscaras) y el aislamiento de las personas con sospecha de infecciones de las vías respiratorias parecen ser las medidas más efectivas.

\section{Ricardo Sarandría [ Médico de Familia, Policlínico Modelo de Cipolletti, Río Negro. ricardo.sarandria@gmail.com ]}

Sarandría R. Intervenciones para la disminución de la transmisión de los virus respiratorios. Evid. actual. práct. ambul; $11(3)$ :68, May-Jun 2008. Comentado de: Jefferson T y col. Physical interventions to interrupt or reduce the spread of respiratory viruses: systematic review. BMJ 2008; 336; 77-80. PMID: 18042961. Disponible en URL: http://www.bmj.com/cgi/content/full/336/7635/77 (último acceso 03/06/08).

\section{Referencia}

1.Terceiro D y Terrasa S. Brote mundial de síndrome respiratorio agudo grave. Evid. actual. práct. ambul; 6(2): 45, Abr-May 2003. Disponible en URL: http://www.foroaps.org/files/sars.pdf Comentado de: Lee N y col. A Major Outbreak of Severe Acute Respiratory Syndrome in Hong Kong. N Engl J Med $20030: 306851$. h Published at www.nejm.org April 7, 2003.

2. Pittet $D$, et al. Evidence-based model for hand transmission during patient care and the role of improved practices. Lancet Infect Dis. 2006;6:641-52. 